https://doi.org/10.36105/iut.2020n32.05

\title{
EL DERECHO A LA DEFENSA ADECUADA EN EL PROCEDIMIENTO DE RESPONSABILIDAD ADMINISTRATIVA
}

\author{
THE RIGHT TO ADEQUATE DEFENSE IN THE \\ ADMINISTRATIVE LIABILITY PROCEDURE
}

Baruch F. Delgado Carbajal* Investigador independiente, México baruch.delgado@tjaem.gob.mx

\section{RESUMEN:}

El propósito del presente análisis es determinar si en las diversas etapas del procedimiento de responsabilidad administrativa, conforme a la Ley General de Responsabilidades Administrativas, derivada de la reforma constitucional del 27 de mayo de 2015, se cumple con el derecho a la defensa técnica y eficaz que como parte del debido proceso es un derecho humano fundamental que debe garantizar la autoridad sancionadora, con apego a los estándares constitucionales y convencionales en la materia.

\section{Palabras clave:}

Procedimiento, responsabilidad administrativa, defensa técnica y eficaz, derecho humano.

\section{ABSTRACT:}

In the administrative liability procedure, in accordance with the new general law on the matter, the right to technical and effective defense is complied, which is a human right.

* Magistrado integrante de la Cuarta Sección Especializada en Materia de Responsabilidades Administrativas del Tribunal de Justicia Administrativa del Estado de México. Fue presidente del Tribunal Superior de Justicia del Estado de México y de la Comisión Nacional de Tribunales Superiores de Justicia de los Estados Unidos Mexicanos. Fue presidente de la Comisión de Derechos Humanos del Estado de México. 


\section{Keywords:}

Procedure, administrative responsibility, technical and effective defense, human right.

SUMARIO: I. Resumen. II. Apunte Introductorio. III. El Derecho Administrativo Sancionador y el Derecho Administrativo Disciplinario. IV. El debido proceso, el derecho de defensa y el derecho a la asistencia jurídica. V. Precedentes de la Corte Interamericana de Derechos Humanos y del Tribunal Europeo de Derechos Humanos, sobre el derecho de asistencia jurídica. VI. Criterios de la autoridad judicial federal sobre el derecho de defensa adecuada. VII. El debido proceso en la Ley General de Responsabilidades Administrativas. VIII. El derecho a la defensa adecuada en la Ley General del Responsabilidades Administrativas. IX. Consideraciones sobre el derecho a la defensa adecuada en las etapas del procedimiento de responsabilidad administrativa, para cumplir con el estándar convencional.

\section{APUNTE INTRODUCTORIO}

Este nuevo régimen de responsabilidades administrativas incorpora las directrices fijadas por instrumentos internacionales ratificados por el estado mexicano, como la Convención Interamericana contra la Corrupción (OEA, 1998), la Convención para Combatir el Cohecho de Servidores Públicos Extranjeros en Transacciones Comerciales Internacionales (OCDE, 1999) y la Convención de las Naciones Unidas contra la Corrupción (UNODC, 2005).

Con base en estas convenciones y en reformas constitucionales previas, el 27 de mayo de 2015 se publicó en el Diario Oficial de la Federación, el Decreto por el que se reforman los artículos 22, 28, 41, 73, 74, 76, 79, 104, 108, 109, 113, 114, 116 y 122 de la CPEUM, la que entre otros aspectos, establece un nuevo régimen de responsabilidades administrativas en el que se confiere competencia a los Tribunales de Justicia Administrativa en el ámbito federal y local, para la imposición de sanciones a servidores públicos y particulares por la comisión de faltas administrativas graves o hechos de corrupción, en tanto que las faltas administrativas no graves quedan bajo el conocimiento y precisión de las secretarías y órganos de control interno.

Se estima que un adecuado régimen de responsabilidades administrativas, que permita su identificación, investigación, substanciación, sanción y ejecución de sanciones, en justo equilibrio entre la potestad punitiva del Estado y el respeto y garantía de los derechos humanos, entre ellos el derecho de defensa como parte del debido proceso, es un paso fundamental para abonar a la solución de esta problemática en un Estado democrático de derecho.

Una fortaleza de los estados constitucionales democráticos consiste en configurar su organización, reconociendo los derechos y libertades fundamentales de las personas, así como proveyendo los mecanismos para su garantía frente al poder público. (Salazar, 2017).

En el procedimiento administrativo sancionador que establece la LGRA, se debe tutelar de manera efectiva a favor del presunto responsable, durante las 
diversas etapas del procedimiento, el derecho a la asistencia jurídica (defensa técnica y eficaz), como parte fundamental del debido proceso, bajo el alcance y estándares del derecho constitucional y convencional.

\section{EL DERECHO ADMINISTRATIVO SANCIONADOR Y EL DERECHO ADMINISTRATIVO DISCIPLINARIO}

El derecho administrativo sancionador, es una atribución propia de la administración que se traduce en la posibilidad jurídica de la imposición de sanciones a los particulares y aún a los funcionarios que infringen sus disposiciones, o a sus servidores que, en el ejercicio de sus funciones, transgreden sus mandatos o desconocen sus prohibiciones. (Ossa, 2000).

Como parte del Derecho Administrativo Sancionador, el derecho disciplinario, se ha definido, como el conjunto de disposiciones sustantivas y adjetivas, contenidas en diversas leyes y normas, las cuales regulan las actividades de los servidores públicos con la finalidad de garantizar el ejercicio adecuado de la función pública, a través de los principios de legalidad, objetividad, profesionalismo, honradez, lealtad, imparcialidad, eficiencia, eficacia, equidad, transparencia, economía, integridad y competencia de mérito, estableciendo mecanismos disciplinarios, garantías y procedimientos para aquellos que las violen (Gándara, 2017).

\section{EL DEBIDO PROCESO, EL DERECHO DE DEFENSA Y EL DERECHO A LA ASISTENCIA JURÍDICA}

El debido proceso legal se refiere al conjunto de requisitos que deben observarse en las instancias procesales a efecto de que las personas estén en condiciones de defender adecuadamente sus derechos ante cualquier acto del Estado que pueda afectarlos. (CoIDH, 2003).

El debido proceso legal es el conjunto de condiciones y requisitos de carácter jurídico y procesal que son necesarios para poder afectar legalmente los derechos de los gobernados (Fix-Zamudio, 1987).

El debido proceso, en concepto propio, es el conjunto de requisitos y formalidades que debe observar la autoridad en todos los procesos y procedimientos de carácter jurisdiccional, en los que se puedan afectar derechos o intereses de los gobernados, con el objetivo de estén en aptitud de defenderse adecuadamente.

La constitución federal reconoce el derecho humano al debido proceso, al establecer que nadie podrá ser privado de la libertad o de sus propiedades, posesiones o derechos, sino mediante juicio seguido ante los tribunales previamente establecidos, en el que se cumplan las formalidades esenciales del procedimiento y conforme a las leyes expedidas con anterioridad al hecho (CPEUM, 1917, artículo 14).

De igual forma, en materia penal establece el derecho a la defensa adecuada por abogado, que deberá elegirse libremente desde la detención; cuando el imputado no quiera o no pueda nombrar abogado, el juez le deberá designar un defensor público; el defensor debe comparecer a todos los actos del proceso (CPEUM, 1917, artículo 20, apartado B, fracción XVIII). 
La Convención Americana sobre Derechos Humanos, reconoce como una garantía judicial, el debido proceso, conforme al cual toda persona tiene derecho a ser oída con las debidas garantías y dentro de un plazo razonable, por un juez o tribunal competente, independiente e imparcial, establecido con anterioridad por la ley, en la sustanciación de cualquier acusación penal o para la determinación de sus derechos y obligaciones de orden civil, laboral, fiscal o de cualquier otro carácter (CADH, 1969, artículo 8.1.).

La CoIDH en diversas resoluciones y desde la Opinión Consultiva OC-9/87 del 6 de octubre de 1987, ha establecido que el debido proceso, es un principio rector obligatorio para las autoridades que materialmente ejerzan funciones jurisdiccionales, es decir, que también las garantías del orden penal son aplicables a las diversas materias, entre ellas, a la materia administrativa.

El Pacto Internacional de Derechos Civiles y Políticos ${ }^{1}$ establece que todas las personas son iguales ante los tribunales y las cortes de justicia, y toda persona tendrá derecho a ser oída públicamente y con las debidas garantías por un tribunal competente, independiente e imparcial, establecido por la ley en la sustanciación de cualquier acusación formulada contra ello o para la determinación de sus derechos u obligaciones de carácter civil y penal. (PIDCP, 1966, artículo 14).

Bajo tal contexto, el derecho de defensa es un derecho fundamental reconocido constitucionalmente y en los textos de derechos humanos, el cual debe salvaguardarse en cualquier procedimiento jurisdiccional. Es parte del debido proceso y requisito esencial de validez del mismo.

Consiste en la posibilidad jurídica y material de ejercer la defensa de los derechos e intereses de la persona, en juicio y ante autoridades, de manera que se asegure la realización efectiva de los principios de igualdad de las partes y de contradicción; constituye un derecho ilimitado, por ser un derecho fundamental absoluto. Justamente, la defensa de la persona en juicio y de sus derechos se concibe solamente a través de la intervención del abogado (Cruz, 2015).

Entre las garantías judiciales del derecho de defensa en el debido proceso que reconoce la Convención Americana sobre Derechos Humanos, encontramos:

d. derecho de defenderse personalmente o de ser asistido por un defensor de su elección y de comunicarse libre y privadamente con su defensor;

e. derecho irrenunciable de ser asistido por un defensor proporcionado por el Estado ..." (CADH, 1969, artículo 8, numeral 2, inciso d y e.

Se debe destacar que en los Principios Básicos sobre la Función de los Abogados, se establece la obligación para los gobiernos de informar, a todas las personas acusadas de haber cometido un delito o detenidas, de su derecho a estar asistidas de un abogado de su elección, así como a que se les asigne abogados con competencia y experiencia para que les presten asistencia jurídica y gratuita, a facilitar oportunidad, tiempo e instalaciones para entrevistarse con un abogado sin demora ni censura y en forma confidencial (PBFA, 1990).

\footnotetext{
Fue adoptado en Nueva York el 16 de diciembre de 1966. México se adhirió el 24 de marzo de 1981. El decreto promulgado se publicó en el Diario Oficial de la Federación del 20 de mayo de 1981 y la fe de erratas en el Diario Oficial de la Federación del 22 de junio 1981.
} 


\section{Caso Chaparro Álvarez y Lapo Íñiguez vs. Ecuador. Sentencia del 21} de noviembre de 2007 (CoIDH, 2007).

La Corte determinó que se violó en agravio del señor Chaparro el derecho a la defensa adecuada, la que se debe garantizar desde la etapa pre procesal; que la asistencia del abogado no debe ser sólo de carácter formal, sino efectiva, para lo cual el Estado debe adoptar todas las medidas adecuadas, en el caso estimó que se violó en perjuicio del señor Lapo el derecho consagrado en el artículo 8.2. e) de la CADH.

\section{Caso Vélez Loor Vs. Panamá. Sentencia del 23 de noviembre 2010 (CoI- DH, 2010).}

El derecho a la asistencia consular y la asistencia letrada son medidas necesarias que los Estados deben adoptar para garantizar un efectivo e igualitario acceso a la justicia de las personas que se encuentran en una situación de vulnerabilidad agravada, como migrante.

Que en procedimientos administrativos o judiciales en los cuales se pueda adoptar una decisión que implique la deportación, expulsión o privación de libertad, la prestación de un servicio público gratuito de defensa legal a favor de estas personas es necesaria para evitar la vulneración del derecho a las garantías del debido proceso.

\section{Caso Barreto Leiva Vs. Venezuela. Sentencia del 17 de noviembre de 2009 (CoIDH, 2009).}

Que el derecho a la defensa técnica surge desde el momento en que se ordena investigar a una persona; que impedir la asistencia del abogado defensor es limitar severamente el derecho a la defensa, lo que ocasiona desequilibrio procesal y deja al individuo sin tutela frente al ejercicio del poder punitivo.

Que el derecho a la defensa técnica no puede ser satisfecho por quien a la postre realizará la acusación, esto es, el Ministerio Público, por lo que no es razonable depositar funciones naturalmente antagónicas en una sola persona.

\section{Caso Ruano Torres y Otros Vs. EI Salvador. Sentencia del 5 de octubre de 2015 (CoIDH, 2015).}

Que este derecho debe ejercerse desde que se señala a una persona como posible autor o partícipe de un hecho punible y sólo culmina cuando finaliza el proceso, incluyendo, la etapa de ejecución de la pena.

Que el derecho a la defensa se proyecta en dos facetas, a través de los propios actos del inculpado a rendir una declaración libre sobre los hechos que se le atribuyen y, por el otro, por medio de la defensa técnica, para ejercer un control crítico y de legalidad en la producción de pruebas.

Que nombrar a un defensor de oficio con el sólo objeto de cumplir con una formalidad procesal equivaldría a no contar con defensa técnica, por lo que es 
importante que dicho defensor actúe de manera diligente con el fin de proteger las garantías procesales del acusado.

Que los Estados deben adoptar medidas adecuadas, para contar con defensores idóneos y capacitados que puedan actuar con autonomía funcional.

Que si es evidente que la defensa pública actuó sin la diligencia debida, recae sobre las autoridades judiciales un deber de tutela o control, ya que la función judicial debe vigilar que el derecho a la defensa no se torne ilusorio a través de una asistencia jurídica ineficaz.

\section{Caso Suárez Rosero contra Ecuador. Sentencia del 12 de noviembre de 1997 (CoIDH, 1997). \\ Que el derecho de defensa del inculpado, a contar con el patrocinio letrado de un defensor público y tener comunicación libre y privada con el abogado, se deber ejercer desde que inicia la investigación, esto es, desde que se señala a una persona como autor o partícipe de uno hecho punible y culmina cuando finaliza el proceso; que de sostener lo contrario implica supeditar las garantías conven- cionales que protegen el derecho a la defensa.} 1980).

\section{Caso Ártico contra Italia. Sentencia del 13 de mayo de 1980 (TEDH,}

El Tribunal Europeo de Derechos Humanos, en esta resolución determinó que: el objetivo primordial del Convenio Europeo de Derechos Humanos consiste en proteger derechos no teóricos ni ilusorios, sino concretos y efectivos, lo que cobra importancia con relación a los derechos de defensa en el derecho a un debido proceso.

Que el sólo derecho a designar una defensa no garantiza el derecho a la asistencia, que por ello cuando se advierta algún impedimento o deficiencia en la defensa, las autoridades deben sustituirlo u obligarle a cumplir con su deber, pues de lo contrario la asistencia letrada se convertiría en un concepto vacío de contenido.

Que en cualquier caso, "el interés de la justicia" exige se provea a una asistencia jurídica efectiva, particularmente a las personas más vulnerables.

Que no es necesario acreditar que la falta de asistencia jurídica debía haber provocado un perjuicio a la persona afectada, ya que una interpretación que introduzca este requisito privaría a la norma de su real contenido. En general, la existencia de la violación existe incluso en ausencia de un perjuicio concreto.

\section{CRITERIOS DE LA AUTORIDAD JUDICIAL FEDERAL SOBRE EL DERECHO DE DEFENSA ADECUADA}

En diversos criterios de la SCJN, se ha establecido que dada la similitud y la unidad de la potestad punitiva, en la interpretación constitucional de los principios del derecho administrativo sancionador pueden acudirse a los principios penales sustantivos, aun cuando la traslación de los mismos en cuanto a grados de exigencia no pueda hacerse de forma automática, porque la aplicación de dichas 
garantías al procedimiento administrativo sólo es posible en la medida en que resulten compatibles con su naturaleza.

En el caso, el derecho a la defensa adecuada debe observarse en el procedimiento administrativo disciplinario, en cumplimiento a las disposiciones legales, constitucionales y convencionales aplicables en la materia; sobre el particular es conveniente precisar algunos criterios al respecto.

1. La defensa adecuada no se satisface con el sólo nombramiento de un licenciado en derecho, sino que se debe verificar por parte del tribunal, que la persona sujeta a un proceso tiene la asistencia de una persona capacitada para defenderlo y que el abogado satisfaga un estándar mínimo de diligencia en el cumplimiento de sus deberes, lo que debe ser controlado por el Juez en su calidad de garante y rector del procedimiento penal. ${ }^{2}$

2. Que el órgano jurisdiccional para verificar el cumplimiento de este derecho, debe evaluar la defensa proporcionada por el abogado, verificando que las deficiencias correspondan a la incompetencia del defensor y no a una intención del inculpado de entorpecer o evadir el proceso, o bien a una estrategia defensiva del abogado; que en estos casos se puede otorgar la posibilidad de cambiar de abogado o asignar uno de oficio, si se decide mantener al defensor particular, el Juez nombrará un defensor público para que colabore en la defensa. ${ }^{3}$

3. Que el derecho a la defensa técnica no debe presumirse, por lo que el carácter de licenciado en derecho debe verificarse, ya que el cumplimiento de este derecho humano debe quedar plena y legalmente acreditado. ${ }^{4}$

4. Que en el auto de admisión de la segunda instancia, debe hacerse constar el nombre del defensor de oficio designado al procesado, así como darse a conocer a éste la identidad del mismo, a fin de que esté en aptitud de reiterar su nombramiento o nombrar uno distinto, con la oportunidad debida para preparar su defensa a efecto de no dejarlo en estado de indefensión. ${ }^{5}$

2 Tesis de Jurisprudencia: 1a. C/2019 (10a.) de la Primera Sala, Décima Época, registro 2021099, visible en la Gaceta del Semanario Judicial de la Federación, Libro 72, noviembre de 2019, Tomo I, Materia(s): Constitucional, Penal, Página: 366, bajo el rubro: DEFENSA ADECUADA EN SU VERTIENTE MATERIAL. NO SE SATISFACE ESTE DERECHO, CON EL SOLO NOMBRAMIENTO DE UN LICENCIADO EN DERECHO PARA LA DEFENSA DEL IMPUTADO, SINO QUE DEBEN IMPLEMENTARSE LAS MEDIDAS NECESARIAS PARA GARANTIZAR QUE TIENE LAASISTENCIA DE UNA PERSONA CAPACITADA PARA DEFENDERLO [ABANDONO PARCIAL DE LA JURISPRUDENCIA 1a./J. 12/2012 (9a.)]

3 Tesis de Jurisprudencia: 1a. CI/2019 (10a.), Primera Sala, registro 2021097, de la Décima Época, visible en la Gaceta del Semanario Judicial de la Federación, Tomo I, noviembre de 2019, Tomo I, Materia(s): Constitucional, Penal, Página: 364, bajo el rubro: DEFENSA ADECUADA EN SU VERTIENTE MATERIAL. DIRECTRICES A SEGUIR PARA EVALUAR SI ESTE DERECHO HA SIDO VIOLADO.

4 Tesis de Jurisprudencia: 1a. CCCXXVIII/2015 (10a.),_Primera Sala, registro 2010350, de la Décima Época, visible en la Gaceta del Semanario Judicial de la Federación, Tomo I, noviembre de 2015, Tomo I, Materia(s): Constitucional, Penal, Página: 966, bajo el rubro: DEFENSA TÉCNICA. NO DEBE PRESUMIRSE POR EL HECHO DE QUE SE ASIENTE EN LA DECLARACIÓN MINISTERIAL DE UN INCULPADO QUE QUIEN LO ASISTE ES DEFENSOR DE OFICIO, SI NO EXISTE SUSTENTO ALGUNO DE ESA CALIDAD.

5 Tesis de Jurisprudencia: III.2o.P.254 P,_Tribunales Colegiados de Circuito, registro 163488, de la Novena Época, visible en la Semanario Judicial de la Federación y su Gaceta, Tomo XXXII, noviembre de 2010, 


\section{EL DEBIDO PROCESO EN LA LEY GENERAL DE RESPONSABILIDADES ADMINISTRATIVAS}

El régimen disciplinario administrativo previsto en la LGRA, busca fortalecer el estado democrático de derecho para el ejercicio de la potestad punitiva del Estado, al establecer un catálogo especifico de faltas no graves y de faltas graves o hechos de corrupción, sancionar tanto a los servidores públicos como a los particulares vinculados con hechos de corrupción, sean personas físicas o jurídico colectivas, y a particulares en situación especial (candidatos a cargos de elección popular, miembros de equipos de campaña electoral o de transición entre administraciones del sector público, líderes de sindicatos del sector público como de sus directivos y empleados); un aspecto que fortalece el debido proceso, es la jurisdiccionalización del derecho administrativo disciplinario, a través de la competencia conferida a los tribunales de justicia administrativa para que por conducto de salas especializadas, impongan sanciones por faltas administrativas graves, tribunales jurisdiccionales que además se configuran como órganos constitucionales autónomos, se establece como obligatoria su creación y competencia tanto para la federación como para las entidades federativas, no dependen de ninguno de los poderes públicos, deben contar con presupuesto propio, así como gozar de independencia y autonomía plena para dictar sus resoluciones, establecer su organización, funcionamiento, procedimientos y recursos contra sus resoluciones.

Estas características y atribuciones para los tribunales de justicia administrativa, desde la base constitucional, fortalecen el estado democrático de derecho y el debido proceso tratándose de responsabilidades administrativas, porque garantizan que sea un tribunal especializado y con plena autonomía financiera y jurisdiccional, el que conozca y decida sobre la responsabilidad administrativa en que pudieran incurrir servidores públicos y particulares relacionados con hechos de corrupción.

En estos términos, el artículo 109 de la CPEUM, establece que la investigación y substanciación de los actos u omisiones que constituyen faltas administrativas graves de servidores públicos y de particulares vinculados con ellas, corresponderá a la Auditoría Superior de la Federación y a los órganos internos de control, así como a sus homólogos en las entidades federativas, y serán resueltas por el Tribunal de Justicia Administrativa que resulte competente (CPEUM, 1917: artículo 109).

La jurisdiccionalización del derecho administrativo disciplinario, fortalece el debido proceso, al respeto la doctrina señala que "una de las garantías de seguridad jurídica del servidor público es el procedimiento administrativo que impone a la autoridad un cauce legal como requisito para la validez de un acto administrativo". (Botassi y Oroz, 2011).

Materia(s): Penal, Página: 1437, bajo el rubro: DEFENSA ADECUADA. SE VULNERA SI DURANTE LA SUSTANCIACIÓN DE LAAPELACIÓN EL INCULPADO NO CONOCIÓ LA IDENTIDAD DEL DEFENSOR DESIGNADO 


\section{EL DERECHO A LA DEFENSA ADECUADA EN LA LEY GENERAL DE RESPONSABILIDADES ADMINISTRATIVAS}

En el procedimiento de responsabilidad administrativa, tanto en el relativo a faltas no graves como en el de faltas graves, el derecho a la asistencia jurídica como parte del derecho de defensa en el debido proceso se encuentra regulado por los artículos 208, fracción II y 209 párrafo segundo de la Ley General de Responsabilidades Administrativas, en los siguientes términos.

En el caso de que la autoridad substanciadora admita el Informe de Presunta Responsabilidad Administrativa, ordenará el emplazamiento del presunto responsable, debiendo citarlo para que comparezca personalmente a la celebración de la audiencia inicial, señalando con precisión el día, lugar y hora en que tendrá lugar dicha audiencia, así como la autoridad ante la que se llevará a cabo. Del mismo modo, le hará saber el derecho que tiene de no declarar contra de sí mismo ni a declararse culpable; de defenderse personalmente o ser asistido por un defensor perito en la materia y que, de no contar con un defensor, le será nombrado un defensor de oficio. (LGRA. artículo 208, fracción II).

Lo anterior impone la obligación a la autoridad substanciadora, para garantizar el derecho a la defensa adecuada, en dos aspectos:

a) Al ordenar el emplazamiento del presunto responsable y citarlo a la audiencia inicial, entre otras cosas, le debe hacer saber, el derecho de defenderse personalmente o ser asistido por un defensor perito en la materia y, además.

b) Que de no contar con defensor, le será nombrado un defensor de oficio.

Con lo anterior, la LGRA, cumple "parcialmente" con el derecho al debido proceso, en cuanto al derecho a la asistencia jurídica, que consagran los artículos 8.1 y 8.2 inciso d) y e) de la CADH.

Cabe destacar, que conforme a la jurisprudencia establecida en diversos criterios de la $\mathrm{CIDH}$, el derecho a la defensa pública es irrenunciable, por lo que, si no cuenta el presunto responsable con un defensor particular perito en la materia, se impone la obligación a la autoridad substanciadora, de designar defensor público.

No obstante lo anterior, a efecto de que se cumpla con el estándar convencional del derecho a una defensa adecuada, se debe de garantizar este derecho, durante todas las etapas del procedimiento administrativo disciplinario.

\section{CONSIDERACIONES SOBRE EL DERECHO A LA DEFENSA ADECUADA EN LAS ETAPAS DEL PROCEDIMIENTO ADMINISTRATIVO DISCIPLINARIO, PARA CUMPLIR CON EL ESTÁNDAR CONVENCIONAL}

\section{A. Etapa de investigación}

1. En términos del artículo 96 de la LGRA, la autoridad investigadora cuenta con facultades para realizar requerimientos a las personas físicas o morales, 
públicas o privadas, que sean sujetos de investigación por presuntas irregularidades cometidas en el ejercicio de sus funciones.

En estos casos, aun cuando la ley no lo prevé, a efecto de garantizar el derecho a la defensa adecuada desde la etapa de investigación, se le debe hacer saber al investigado en el acto del requerimiento, el derecho que le asiste de no autoincriminarse y de asesorarse por abogado perito en la materia, que de no contar con abogado particular tienen derecho a que le sea nombrado defensor público por la autoridad requirente.

2. Conforme al artículo 100 de la LGRA, "Concluidas las diligencias de investigación, las autoridades investigadoras procederán al análisis de los hechos, así como de la información recabada, a efecto de determinar la existencia o inexistencia de actos u omisiones que la ley señale como falta administrativa y, en su caso, calificarla como grave o no grave".

Cuando se tenga identificado a un presunto responsable, a efecto de garantizar la defensa adecuada desde la etapa de investigación, de manera previa a la determinación sobre la existencia de actos u omisiones que constituyan una falta administrativa, para garantizar la asistencia técnica desde la etapa de investigación, la ley debe regular que la autoridad investigadora cite a una audiencia previa al presunto responsable, para que comparezca asistido de defensor perito en la materia o en su defecto de defensor público que se le designe, acto en el que se le deberán hacer saber los hechos o motivos de una presunta responsabilidad, para que esté en aptitud de manifestar lo que a su derecho convenga.

\section{B. Etapa de substanciación}

Conforme al artículo 208, fracción II de la LGRA, la autoridad substanciadora al ordenar el emplazamiento del presunto responsable y citarlo a la audiencia inicial, entre otros aspectos, le hará saber el derecho que tiene a defenderse personalmente o ser asistido por un defensor perito en la materia y que de no contar con defensor, le será nombrado un defensor de oficio.

Además de lo anterior, la autoridad substanciadora deberá dar cumplimiento a los siguientes puntos:

1. En la audiencia inicial, la autoridad substanciadora, deberá asentar que verificó que el defensor designado por el presunto responsable, tenga el carácter de licenciado en derecho, verificando los datos que acrediten su carácter de profesional del derecho.

2. En todos los actos procesales donde intervenga el presunto responsable, particularmente en el desahogo de pruebas, se debe hacer constar la presencia del abogado defensor.

3. La autoridad substanciadoras o resolutora, deberá verificar que los actos de defensa sean eficaces, en su caso, requerir al defensor particular o público realice los actos que acrediten una defensa eficaz; hacer saber al presunto responsable el derecho de sustituir a su defensor particular, de no aceptar, nombrarle un defensor público para que colabore en la defensa. 
4. La autoridad substanciadora o resolutora deberán constatar que el defensor particular o público, hayan tenido el tiempo suficiente para imponerse de las actuaciones, en su caso suspender la audiencia y fijar nueva fecha.

\section{Etapa de resolución}

Al dictar resolución, el órgano interno de control o el Tribunal de Justicia Administrativa, deberán analizar si durante las etapas de investigación y substanciación, se cumplió con el derecho a la defensa adecuada que las disposiciones legales, constitucionales y convencionales, reconocen a favor del servidor público o particular a quien se le atribuye la comisión de una falta administrativa.

En caso de advertir que al procesado no se le garantizo el derecho a una defensa adecuada, estará en aptitud de ordenar la reposición del procedimiento a partir del acto procedimental en que se transgredió ese derecho.

\section{Etapa impugnativa}

Cuando se interponga el recurso de apelación en términos de los artículos 215, 216, 217 y 218 de la LGRA, el tribunal que conozca de la apelación, al admitir el recurso deberá verificar que el presunto responsable, cuente con asistencia jurídica para el trámite de este recurso o bien requerirlo para que designe defensor particular y en caso de no hacerlo, se le nombre defensor de oficio, con la finalidad de no dejarlo en estado de indefensión durante el trámite de la segunda instancia.

\section{E. Etapa de ejecución}

En la etapa de ejecución de la sentencia, también debe garantizarse al sancionado, el derecho a la asistencia jurídica, particularmente cuando se pueda afectar un derecho en exceso o en defecto de la ejecutoria respectiva.

\section{FUENTES CONSULTADAS}

BOTASSI, C. y OROZ, M. (2011), Procedimiento Administrativo de la Provincia de Buenos Aires. La Plata: Platense.

CADH (Convención Americana sobre Derechos Humanos) (1969), Suscrita en la Conferencia Especializada Interamericana sobre Derechos Humanos, San José de Costa Rica, 22 de noviembre de 1969.

CoIDH (Corte Interamericana de Derechos Humanos) (1997), Caso Suárez Rosero vs. Ecuador, sentencia de 12 de noviembre de 1997.

CoIDH (Corte Interamericana de Derechos Humanos) (2003). Opinión Consultiva OC-18/03.

CoIDH (Corte Interamericana de Derechos Humanos)(2007), Caso Chaparro Álvarez y Lapo Íñiguez vs. Ecuador, sentencia de 21 de noviembre de 2007. 
CoIDH (Corte Interamericana de Derechos Humanos) (2009), Caso Barreto Leiva vs. Venezuela, sentencia del 17 de noviembre de 2009.

CoIDH (Corte Interamericana de Derechos Humanos) (2010), Caso Vélez Loor vs Panamá, sentencia del 23 de noviembre de 2010.

CoIDH (Corte Interamericana de Derechos Humanos) (2015), Caso Ruano Torres y Otros vs. El Salvador, sentencia de 5 de octubre de 2015.

COSSÍO DÍAZ, J. (coord.), (2017), Constitución Politica de los Estados Unidos Mexicanos Comentada I, México, Tirant lo Blanch.

CPEUM (Constitución Política de los Estados Unidos Mexicanos) (1917), Diario Oficial de la Federación, 05 de febrero de 1917, última reforma: 06 de marzo de 2020.

CRUZ, O. (2015), Defensa a la defensa y abogacía en México, primera edición, México, UNAM.

Decreto de reformas y adiciones al Título Cuarto, que comprende los artículos del 108 al 114; así como los artículos 22, 73 fracción VI base 4a., 74 fracción V, 76 fracción VII, 94, 97, 127 y 134 de la Constitución Política de los Estados Unidos Mexicanos, Diario Oficial de la Federación, 28 de diciembre de 1982, http://dof.gob.mx/nota_detalle.php?codigo $=4787349 \&$ fecha $=28 / 12 / 1982$, agosto de 2018.

FIX-ZAMUDIO, H. (1987), Diccionario Jurídico Mexicano, México, PorrúaUNAM.

GÁNDARA, A. (2017), Derecho Disciplinario Mexicano: Nuevo Sistema Nacional Anticorrupción, segunda edición, México, Porrúa.

OCDE (Organización para la cooperación y el Desarrollo Económicos) (1999) Convención para Combatir el Cohecho de Servidores Públicos Extranjeros en Transacciones Comerciales Internacionales.

OEA (Organización de los Estados Americanos) (1998) Convención Interamericana Contra la Corrupción.

OSSA, Jaime. (2000), Derecho Administrativo Sancionador. Hacia una teoría general y una aproximación para su autonomía. Colombia, Legis.

PBFA (Principios Básicos sobre la Función de los Abogados) (1990) Adopción: Octavo Congreso de las Naciones Unidas sobre Prevención del Delito y Tratamiento del Delincuente, La Habana, Cuba, 07 de septiembre de 1990.

PIDCP (Pacto Internacional de Derechos Civiles y Políticos), (1966), en vigor el 23 de marzo de 1976.

SALAZAR, P. (2017), El Poder Ejecutivo en la Constitución Mexicana: Del Metaconstitucionalismo a la Constelación de Autonomías, primera edición, México, Fondo de Cultura Económica.

TEDH (Tribunal Europeo de Derechos Humanos) (1980), Caso Ártico contra Italia, sentencia de 13 de mayo de 1980.

UNODC (Oficina de las Naciones Unidas Contra la Droga y el Delito) (2005) Convención de las Naciones Unidas contra la Corrupción. 